lized this approach rather than isolated early pancreatic transplantation as a way to improve graft survival (Table 1). We believe therefore that patients with Type 1 diabetes could be good candidates for pancreatic transplantation if they have already had a successful kidney transplant or if they have such severe diabetic nephropathy that a synchronous kidney and pancreatic transplant would be indicated.

Yours sincerely,

L. H. Toledo-Pereyra

\section{References}

1. Kelly WD, Lillihei RC, Merkel FK, Idezuki Y, Goetz FC (1967) Allotransplantation of the pancreas and duodenum along with the kidney in diabetic nephropathy. Surgery 61:827-837

2. McMaster P, Gibby OM, Calne RY, Loke SP, Luzio SD, Rolles K, White DJG, Evans DB (1980) Human pancreatic transplantation - preliminary studies of carbohydrate control. Transplant Proc 8:371-373
3. Traeger J, Dubernard JM, Tauraine JL, Neyra P, Malik MC, Pillisand C, Ruitton A (1979) Pancreatic transplantation in man: A new method of pancreas preparation and results on diabetes correction. Transplant Proc 11:331-335

4. Gliedman ML, Tellis VA, Soberman R, Rifkin H, Veith FJ (1978) Long term effects of pancreatic transplant function in patients with advanced juvenile-onset diabetes mellitus. Diabetes Care 1: $1-9$

5. Sutherland DER, Goetz FC, Najarian JS (1980) Clinical segmental pancreas transplantation without duct anastomosis in diabetic renal allograft recipients. Diabetes 29: 10-18

6. Goetz FC (1980) Early experiments in human pancreas transplantation. Diabetes 29:1-2

7. Groth CG, Lundgren G, Ostman J, Gunnarson R (1980) Experience with nine segmental pancreatic transplantation in preuremic patients in Stockholm. Transplant Proc 12: 68-71

\author{
L. H. Toledo-Pereyra \\ Department of Surgery \\ Mount Carmel Mercy Hospital \\ Detroit, MI 48235, USA
}

\title{
Pancreatic Transplantation and the Artificial Pancreas
}

Dear Sir

I was impressed by the in-depth studies performed by Drs. Strubbe and van Wachem to investigate the physiological role of the autonomic nervous system on insulin secretion (Diabetologia $20: 228-236$ ). Their model is elegant and gave results which enabled them to discuss the possibility that the delayed insulin response in the transplanted rats resembled the insulin response of human prediabetics in whom a lower first phase response with a delayed and sometimes higher second phase response is seen. I was particularly struck when the authors speculated that not only the early phase insulin release seems to be of physiological importance in glucose homeostatis, but also the second phase release. These studies in a transplanted animal model confirm for the first time observations which we made on pancreatectomized dogs treated with an artificial endocrine pancreas [1].

In those studies, we observed that standardised glucose challenges consisting of uniform infusions of $10 \mathrm{mg}$ glucose $\mathrm{kg}^{-1} \mathrm{~min}^{-1}$ for $60 \mathrm{~min}$ resulted in a glycaemic response to the challenge resembling mild maturity-onset diabetes. When the device was programmed to respond not only to the level of glycaemia, but also to the rate of change of glycaemia, the abnormal rise in glycaemia was prevented. The studies with the artificial pancreas indicated that an anticipatory action of the endocrine pancreas was instrumental in achieving the fine regulation seen in healthy subjects. It is interesting that the work of Strubbe and van Wachem indicated clearly that the absence of input from the autonomic nervous system on insulin secretion which occurs when pancreas is transplanted results in similar abnormalities.

In some ways it is rather disappointing that the transplanted pancreas and the closed-loop artificial pancreas both appear to suffer from the deprivation of the neurological input from the autonomic nervous system. It will be interesting to see whether the open-loop device which uses neurological inputs of a higher order, from the central nervous system as it were, will in fact be able to overcome this significant deficiency.

Yours sincerely,

A. M. Albisser

\section{Reference}

1. Albisser AM, Leibel BS, Ewart TG, Davidovac Z, Botz CK, Zingg W (1974) An artificial endocrine pancreas. Diabetes 23: 389-396

A. M.Albisser, Ph.D.

Division of Biomedical Research

The Hospital for Sick Children

Toronto M5G 1X8, Canada 